\title{
Reduction of tris(benzene-1,2-dithiolate)molybdenum(vi) by hydroxide ions in dry tetrahydrofuran solution
}

\author{
Antonio Cervilla, ${ }^{* a}$ Francisco Pérez-Pla ${ }^{b}$ and Elisa Llopis ${ }^{a}$ \\ a Departamento de Química Inorgànica, ICMUV, PO Box 2085, Polígono La Coma, Paterna, Valencia, \\ Spain.E-mail: Antonio Cervilla@.uv.es; Fax: 34963983633 \\ b Departamento de Química-Física, Universidad de Valencia, Dr. Moliner 50, 46100-Burjasot, Valencia, \\ Spain
}

\section{Received (in Cambridge, UK) 10th July 2001, Accepted 4th October 2001 First published as an Advance Article on the web 25th October 2001}

Tris(benzene-1,2-dithiolate)molybdenum(vi) reacts rapidly and quantitatively with tetrabutylammonium hydroxide to yield the corresponding Mo(v) and Mo(Iv) complexes and hydrogen peroxide; the reaction has been executed in dry tetrahydrofuran where the reaction rate shows a fair dependence on complex and $\mathrm{OH}^{-}$concentrations.

Tris(dithiolene) complexes of transition metals have been the subject of considerable attention since they were first reported. ${ }^{1}$ While early interest focused primarily on the facile one-electron redox reactions which these complexes undergo, more recently the scope has expanded to areas ranging from bioinorganic chemistry to materials science. ${ }^{2}$

Surprisingly little is known about the interaction of this class of compounds with hydroxide ions. Kawashima et al. ${ }^{3}$ first reported the reduction of neutral $\mathrm{M}(\mathrm{tdt})_{3}$ complexes $(\mathrm{M}=\mathrm{Re}$, Mo, and $\mathrm{W}$; tdt = toluene-3,4-dithiolate) dissolved in acetone or THF by aqueous $\mathrm{NaOH}$, but little more than the formation of the corresponding one-electron reduced complex was described. Confirmation of the occurrence of this reaction was subsequently provided by Sellmann et al. ${ }^{4}$ who reacted $\mathrm{Mo}(\mathrm{bdt})_{3}$ (bdt $=$ benzene-1,2-dithiolate) with $\mathrm{NaOH}$ in methanol. The reaction yields the $\left[\mathrm{Mo}(\mathrm{bdt})_{3}\right]^{-}$or $\left[\mathrm{Mo}(\mathrm{bdt})_{3}\right]^{2-}$ complex, depending upon the ratio in which $\mathrm{NaOH}$ and $\mathrm{Mo}(\mathrm{bdt})_{3}$ are mixed, and it was thought to proceed by oxidation of methanol to methanal, although this hypothesis has not been tested.

We were surprised to find that addition of $n-\mathrm{Bu}_{4} \mathrm{NOH}$ to a THF solution of neutral $\mathrm{Mo}(\mathrm{bdt})_{3}$ caused its conversion to the monoanionic $\left[\mathrm{Mo}(\mathrm{bdt})_{3}\right]^{-}$complex and then to the dianionic
$\left[\mathrm{Mo}(\mathrm{bdt})_{3}\right]^{2-}$ complex. All these complexes have been thoroughly characterised elsewhere in solid 5 and in solution. ${ }^{4}$ Because the whole reaction was complete in less than $20 \mathrm{~s}$ in excess of base, both reduction processes have been studied by stopped-flow spectrophotometry. A general treatment of spectrophotometric data has been used to investigate the kinetics of the reaction. The solution absorption spectra of authenticated $\operatorname{Mo}(\mathrm{VI}), \operatorname{Mo}(\mathrm{v})$, and Mo(Iv) complexes were fitted to a Gaussian function basis set within the $400-800 \mathrm{~nm}$ region. ${ }^{6}$ The calculated optical densities $\varepsilon_{i}(\lambda)$ were used to analyse the $\mathrm{Mo}$ (bdt) ${ }_{3}-n-\mathrm{Bu}_{4} \mathrm{NOH}$ system spectrum at each time and to deduce the variation of molybdenum complex concentrations with time. $\dagger$ In all cases the sums of the Mo complex concentrations were equal to the initial $\mathrm{Mo}(\mathrm{bdt})_{3}$ concentration and the resulting $c_{i} v s$. time curves were subject to further kinetic analysis by using a non-linear least-squares method. ${ }^{7}$

The monitoring of an equimolecular $\mathrm{Mo}(\mathrm{bdt})_{3}-n-\mathrm{Bu}_{4} \mathrm{NOH}$ reaction system is presented in Fig. 1a. On the basis of comparisons with authentic samples of $\mathrm{Mo}(\mathrm{bdt})_{3}$ and $\left[\mathrm{Mo}(\mathrm{bdt})_{3}\right]^{-}$, it was concluded that the latter complex is the only molybdenum product formed. This was further supported by HPLC which enabled the separation of $\mathrm{Mo}(\mathrm{bdt})_{3}$ from $\left[\mathrm{Mo}(\mathrm{bdt})_{3}\right]^{-}$in a reaction mixture where no other peaks were detected. Finally, GC-FID did not show peaks other than that from the THF, indicating that this solvent is not involved in the redox process.

All evidence indicates that no absorbing intermediates are formed in appreciable quantities. First, as can be seen in Fig. 1, repetitive UV-Vis scans show tight isosbestic behaviour. Secondly, and more significantly, the kinetics treatment

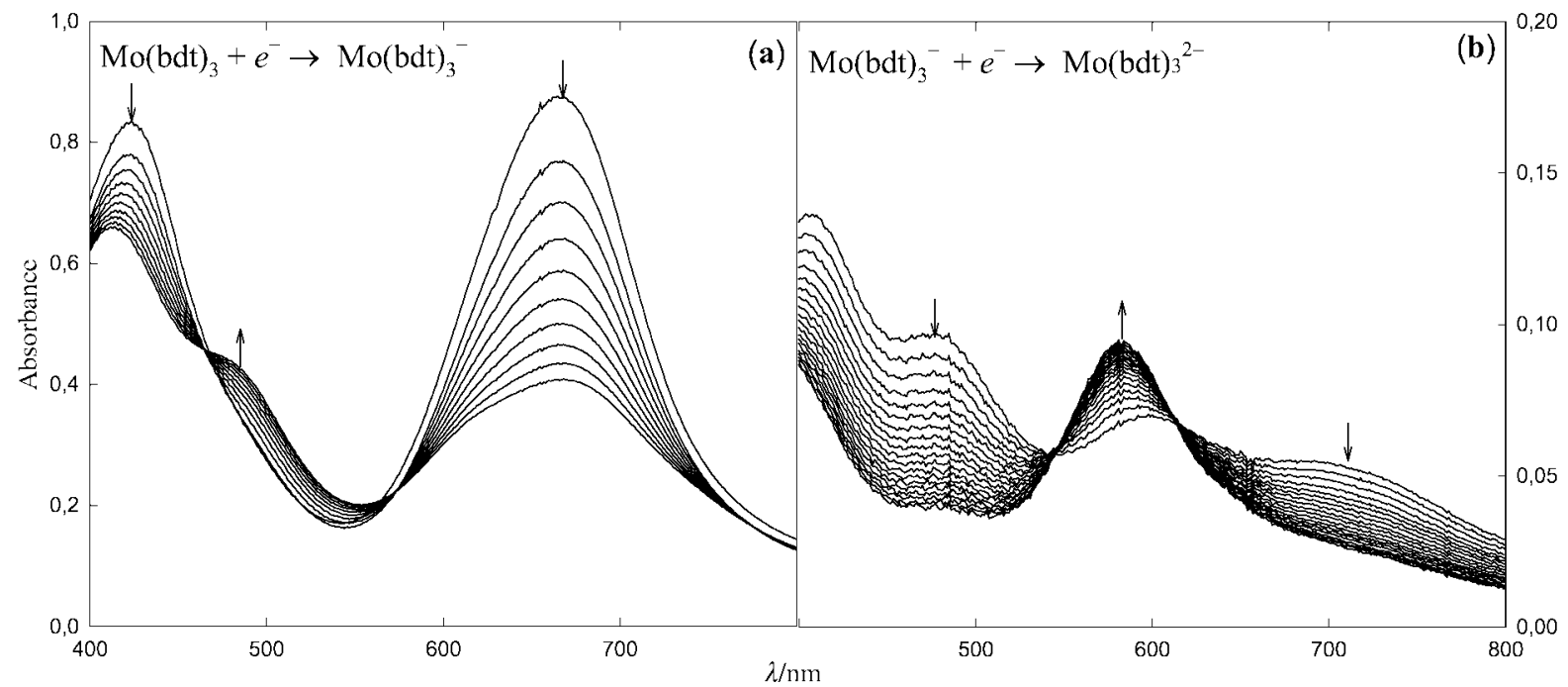

Fig. 1 Repetitive diode-array UV-scans from reaction mixtures in dry THF containing: (a) Mo(bdt) $33.38 \times 10^{-5} \mathrm{~mol} \mathrm{dm}^{-3}$ and $n$-Bu $\mathrm{Bu}_{4} \mathrm{NOH}_{3.38} \times 10^{-5}$

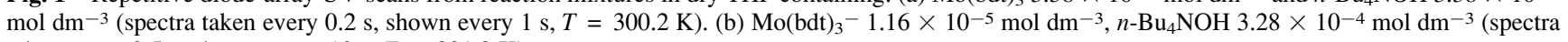
taken every $0.5 \mathrm{~s}$, shown every $10 \mathrm{~s}, T=301.2 \mathrm{~K}$ ). 
described here is capable of reproducing any of these experimental spectra satisfactorily by using only the component Gaussian functions of the $\mathrm{Mo}(\mathrm{bdt})_{3}$ and $\mathrm{Mo}(\mathrm{bdt})_{3}-$ spectra.

The kinetics of the $\mathrm{Mo}(\mathrm{vI})-\mathrm{Mo}(\mathrm{v})$ transformation were investigated with $\mathrm{Bu}_{4} \mathrm{NOH}-\mathrm{Mo}(\mathrm{bdt})_{3}$ mole ratios of $0.4-1.3$. At higher ratios, a further reduction of the formed $\mathrm{Mo}(\mathrm{v})$ complex with excess $n-\mathrm{Bu}_{4} \mathrm{NOH}$ led to the Mo(Iv) complex. Because of this limitation on the ratio of reactants, the kinetics data were treated in complete form, fitting the $\mathrm{Mo}(\mathrm{vI})$ and $\mathrm{Mo}(\mathrm{v})$ concentration $v s$. time curves to the integrated form of the $\mathrm{d}\left[\mathrm{Mo}^{\mathrm{VI}}\right] / \mathrm{dt}=-k\left[\mathrm{Mo}^{\mathrm{VI}}\right]^{p}\left[\mathrm{OH}^{-}\right]^{q}$ equation by using non-linear regression methods. An excellent fit was obtained over a wide range of conditions for $p=2, q=1$, and $k=(5.0 \pm 0.2) \times 10^{8}$ $\mathrm{s}^{-1} \mathrm{~mol}^{-2} \mathrm{dm}^{6}$ at $27^{\circ} \mathrm{C}$. Reaction orders were also corroborated by applying the initial rate method.

The second-order dependence on $\left[\mathrm{Mo}(\mathrm{bdt})_{3}\right]$ suggests a twoelectron reduction of hydroxide ions to hydroperoxide ions that were actually identified in separate experiments [reaction (1)].

$2 \mathrm{Mo}(\mathrm{bdt})_{3}+3 \mathrm{OH}^{-} \rightarrow 2 \mathrm{Mo}(\mathrm{bdt})_{3}{ }^{-}+\mathrm{HO}_{2}{ }^{-}+\mathrm{H}_{2} \mathrm{O}$ (1)

The experiments were performed in biphasic systems by dissolving $\mathrm{Mo}(\mathrm{bdt})_{3}$ in the organic phase and extracting the produced $\mathrm{H}_{2} \mathrm{O}_{2}$ as $\mathrm{HO}_{2}-$ in the aqueous basic phase. Thus, when a $2.0 \times 10^{-3} \mathrm{M}$ solution of $\mathrm{Mo}(\mathrm{bdt})_{3}$ in $\mathrm{THF}$-toluene mixture $(70: 30)$ was added to a $0.1 \mathrm{M}$ aqueous solution of $\mathrm{NaOH}$ over a period of $4 \mathrm{~h}, \mathrm{H}_{2} \mathrm{O}_{2}$ could be detected and spectrophotometrically analysed by reacting an aliquot of the aqueous phase with a solution of $\mathrm{TiOSO}_{4}$ in $25 \% \mathrm{H}_{2} \mathrm{SO}_{4}-\mathrm{H}_{2} \mathrm{O}$. The transmittance at $405 \mathrm{~nm}$ due to the yellow peroxotitanyl cation indicated the presence of $\mathrm{H}_{2} \mathrm{O}_{2}$ in yields of $80-90 \%$ based on the initial $\mathrm{Mo}(\mathrm{bdt})_{3}$ concentration, while no formation of $\mathrm{H}_{2} \mathrm{O}_{2}$ was detected in the absence of $\mathrm{Mo}(\mathrm{bdt})_{3}$.

The second-order dependence on $\left[\mathrm{Mo}(\mathrm{bdt})_{3}\right]$ is consistent with a mechanism having a bimolecular Mo complex interaction as the rate-limiting step. Taking into account that the current spectrophotometric results do not show that $\mathrm{OH}^{-}$binds to Mo through the oxygen, we suggest as a reasonable pathway the association of one hydroxide ion with two neutral Mo(bdt $)_{3}$ molecules by hydrogen bonding to the co-ordinated sulfur atoms of the ligands. $\$ 1,2$ The $\mu$-hydroxo $\mathrm{Mo}(\mathrm{bdt})_{3} \cdots \mathrm{HO}^{-}$ ..Mo(bdt $)_{3}$ species thus formed may pass through a highly concerted transition state in which the interaction with another $\mathrm{OH}^{-}$ion would lead to a polar group-transfer reaction, ${ }^{8}$ dominated by $\mathrm{HO} \cdots \mathrm{OH}$ bond making and metal reduction, to yield the $\left[\mathrm{Mo}(\mathrm{bdt})_{3}\right]^{-}$radical $\left(\langle g\rangle=2.006\right.$; $\langle A\rangle\left({ }^{95,97 \mathrm{Mo})}\right.$ $\left.=26.6 \times 10^{-4} \mathrm{~cm}^{-1}\right)$ and $\mathrm{H}_{2} \mathrm{O}_{2} \ddagger^{3}$ which in basic solution forms the $\mathrm{HO}_{2}-$ ion. An Eyring plot of the rate constant $k$ determined at a series of temperatures gives an excellent straight line from which $\Delta H^{\neq}=37.9 \pm 0.8 \mathrm{~kJ} \mathrm{~mol}^{-1}$ and $\Delta S^{\neq}$ $=-39 \pm 3 \mathrm{~J} \mathrm{~K}^{-1} \mathrm{~mol}^{-1}$ are deduced. The $\Delta S^{\neq}$value is consistent with the proposed associative transition-state.

As estimated from standard reduction potential data, the overall reaction (1) must be exergonic at least in acetonitrile solution. In fact, the redox potential for the reduction of $\mathrm{HO}_{2}^{-}$ to $\mathrm{OH}^{-}$ions has been reported to be $-0.11 \mathrm{~V} v s$. ENH, [1 M $\left.\left(\mathrm{Bu}_{4} \mathrm{~N}\right) \mathrm{OH}, \mathrm{pH} 30.4\right],{ }^{8}$ whereas the measured redox potential for the $\mathrm{Mo}(\mathrm{bdt})_{3}-\mathrm{Mo}(\mathrm{bdt})_{3}-$ pair was found to be $+0.610 \mathrm{~V}$ by cyclic voltammetry. 5 Thus, reaction (1) lies indeed far to the right.

However, the $[\mathrm{Mo}(\mathrm{bdt}) 3]^{1-/ 2-}$ reduction potential is considerably more negative $(-0.040 \mathrm{~V})$ than that of the $\left[\mathrm{Mo}(\mathrm{bdt})_{3}\right]^{0 / 1}-$ couple, and thus the former reduction must have a smaller driving force and a relatively slower reactivity. This was confirmed by monitoring the reaction of $\left(\mathrm{Bu}_{4} \mathrm{~N}\right)$ $\left[\left(\mathrm{Mo}(\mathrm{bdt})_{3}\right]\right.$ with $\mathrm{Bu}_{4} \mathrm{NOH}$, which also proceeds cleanly with well-defined isosbestic points upon addition of excess base (Fig. 1b). By using the procedure indicated above, these spectra were simulated and the concentration of each complex evaluated as a function of time. The disappearance rate of $\left[\mathrm{Mo}(\mathrm{bdt})_{3}\right]^{-}$parallels the appearance rate of $\left[\mathrm{Mo}(\mathrm{bdt})_{3}\right]^{2-}$ for all runs, but it should be noted that both rates become negligible a few seconds after the reaction starts $(\mathrm{ca} .15 \mathrm{~s})$, and also that a complete conversion does not take place even when an excess of $c a$. 20 equivalents of base are initially present. These observations can be plausibly explained when the equilibrium shown in reaction (2) is assumed.

$2 \mathrm{Mo}(\mathrm{bdt})_{3}{ }^{-}+3 \mathrm{OH}^{-} \rightleftharpoons 2 \mathrm{Mo}(\mathrm{bdt})_{3}^{2-}+\mathrm{HO}_{2}{ }^{-}+\mathrm{H}_{2} \mathrm{O}$

Support for the occurrence of this equilibrium comes from the fact that final complex concentrations are dependent on the initial $\mathrm{Bu}_{4} \mathrm{NOH}$ concentration $\left(K=(1.2 \pm 0.3) \times 10^{3} \mathrm{~mol}^{-1}\right.$ $\mathrm{dm}^{3}$ at $\left.298 \mathrm{~K}\right)$. A first analysis of the kinetic data seems to indicate a reversible process in which the rate of $\left[\mathrm{Mo}(\mathrm{bdt})_{3}\right]^{-}$ reduction is first-order in both $\left[\mathrm{Mo}(\mathrm{bdt})_{3}\right]^{-}$and $\left[\mathrm{Mo}(\mathrm{bdt})_{3}\right]^{2-}$ concentrations, being the rate constants dependent on the concentration of base.

In summary, on the basis of this and other works, $, 3,4$ it should no longer be considered unusual to react a higher valent molybdenum tris(dithiolene) compound with hydroxide ions to produce a lower valent molybdenum tris(dithiolene) compound. Moreover, such electron-transfer processes have also been observed to occur with tungsten, e.g. W(bdt $)_{3}$, and this will be the basis of a later publication. Further investigations of the reactivity of $\mathrm{Mo}(\mathrm{bdt})_{3}$ and related compounds in solvents other than THF may clarify whether the observed reactivity is relevant to that of molybdenum cofactor (Moco). ${ }^{2}$

\section{Notes and references}

† The molybdenum complex concentrations were calculated by minimising the following least-squares equation with respect to the concentration of the Mo(vI-IV) complexes:

$$
\phi\left(c_{1}, c_{2}, \ldots, c_{n} ; \lambda\right)=\sum_{k=1}\left(A\left(\lambda_{k}\right)-l \sum_{i=1} \varepsilon_{i}\left(\lambda_{k}\right) c_{i}\right)^{2}
$$

where $A(\lambda)$ is the reaction mixture absorbance at wavelength $\lambda, l$ is the optical pathway, and $\varepsilon_{i}(\lambda)$ and $c_{i}, i \in\{1 \ldots 3\}$, are the optical densities and concentrations of $\mathrm{Mo}(\mathrm{bdt})_{3}, \mathrm{Mo}(\mathrm{bdt})_{3}{ }^{-}$, and $\mathrm{Mo}(\mathrm{bdt})_{3}{ }^{2-}$ species. The calculations were performed using the $\mathrm{C}++$ Linux programs GssKin and GssFit. Free copies of the program are supplied under request.

$$
\begin{aligned}
& \ddagger \text { (1) } \mathrm{Mo}(\text { bdt })_{3}+\mathrm{OH}^{-} \underset{k_{-1}}{\stackrel{k_{1}}{\rightleftharpoons}} \mathrm{Mo}(\text { bdt })_{3} \cdots \mathrm{OH}^{-} \text {(fast) } \\
& \text { (2) } \mathrm{Mo}(\text { bdt })_{3} \cdots \mathrm{OH}^{-}+\mathrm{Mo}(\mathrm{bdt})_{3} \underset{k_{-2}}{\stackrel{k_{2}}{\rightleftharpoons}} \mathrm{Mo}(\text { bdt })_{3} \cdots \mathrm{OH}^{-} \cdots \mathrm{Mo}(\text { bdt })_{3} \text { (fast) } \\
& \text { (3) } \mathrm{Mo}(\mathrm{bdt})_{3} \cdots \mathrm{OH}^{-} \cdots \mathrm{Mo}(\mathrm{bdt})_{3}+\mathrm{OH}^{-} \stackrel{k_{3}}{\longrightarrow} 2 \mathrm{Mo}(\text { bdt })_{3}-+\mathrm{H}_{2} \mathrm{O}_{2} \text { (rls) }
\end{aligned}
$$

1 R. P. Burns and C. A. McAuliffe, Adv. Inorg. Chem. Radiochem., 1979, 22, 303; J. A. McCleverty, Progr. Inorg. Chem., 1968, 10, 49.

2 C. Collison, C. D. Garner and J. A. Joule, Chem. Soc. Rev., 1996, 25, 25; P. Falaras, C. Mitsopoulou, D. Argyropoulos, E. Lyris, N. Psaroudakis, E. Vrachnou and D. Katakis, Inorg. Chem., 1995, 34, 4536 and references therein.

3 M. Kawashima, M. Koyama and T. Fujinaga, J. Inorg Nucl. Chem., 1976, 38, 801 .

4 D. Sellmann and L. Zapf, Z. Naturforsch. B, 1985, 40B, 380.

5 A. Cervilla, E. Llopis, D. Marco and F. Pérez-Pla, Inorg. Chem., in press.

6 P. Gans, Data Fitting in the Chemical Sciences, John Wiley \& Sons, Chichester, 1992, chap. 8.

7 F. F. Pérez Pla, J. F. Bea Redón and R. Valero, Chemometrics and Intelligent Laboratory Systems, 2000, 53, 1.

8 J. A. McCleverty, Encyclopedia of Inorganic Chemistry, ed. R. B. King, John Wiley \& Sons, New York, 1994, p. 2304 